\title{
The percentage of depressive symptoms in patients with type 2 Diabetes Mellitus in M Djamil General Hospital Padang, Indonesia
}

\author{
Eva DECROLI $1 *$ (D), Alexander KAM 1 (D), Dwisari DILlASAMOLA 2 (D) \\ 1 Department of Internal Medicine, Faculty of Medicine, Andalas University, Padang, Indonesia. \\ 2 Department of Pharmacy, Faculty of Pharmacy, Andalas University, Padang, Indonesia. \\ * Corresponding Author. E-mail: evadecroli@med.unand.ac.id (E.D.); Tel. +62-812-661 0524.
}

Received: 23 June 2018 / Revised: 23 August 2018 / Accepted: 23 September 2018

\begin{abstract}
The objectives of this study are to find the percentage of depressive symptoms and the most appeared clinical manifestation of depressive symptoms. A total of 2016 patient with type 2 diabetes from M Djamil General Hospital had fulfilled the questionnaire we administered. Demographic and clinical data were determined from the patient's medical records. Depressive symptoms defined by The Center for Epidemiologic Studies Depression ScaleRevised (CESD-R) score of 16 or higher. CESD-R consisted of nine symptoms group and a 20-item questionnaire. These symptoms groups in patients with depressive symptoms will be counted. Patients with depressive symptoms were grouped based on a type of diabetic medication they consumed (diet only, oral antidiabetic, and insulin) and diabetic complication. From 2016 patients participated in this study, we found 235 (11.7\%) patients were having depressive symptoms. The most appeared clinical manifestation in 235 patients with depressive symptoms is fatigue ( $88.08 \%)$, loss of interest $(52.34 \%)$, sadness $(41.7 \%)$, poor concentration $(40.42 \%)$, and agitation $(23.83 \%)$. There are more depressive symptoms in patients consuming oral antidiabetic drug than patients using insulin and diet only (70.2 vs. 28.1 vs $1.7 \%)$. More depressive symptoms are also found in patients with diabetic nephropathy than patients with diabetic neuropathy and heart disease (52.8 vs. 27.7 vs. 19.6\%). These findings showed that there are many depressive symptoms in patients with T2DM, and some of most appeared clinical manifestation in depressive symptoms should be considered.
\end{abstract}

KEYWORDS: Diabetes; depressive symptoms; oral antidiabetic; insulin; clinical manifestation.

\section{INTRODUCTION}

Depressive symptoms are a frequent co-morbid condition in diabetes. Approximately $30 \%$ of diabetes patients report significantly elevated depressive symptoms and one-third of these patients fulfill the diagnostic criteria of a major depressive disorder. The presence of depressive symptoms in T2DM will worsen the achievement of treatment targets, glycemic control, and quality of life. The World Health Organization (WHO) predicted that by the year 2020, depression will take the second rank in global disease burdens, in this case including diabetic patients [1,2].

With a population of 237.6 million people in 2010, Indonesia is the world's fourth most populated country. It also has the seventh largest number of diabetic patients (7.6 million), despite relatively low prevalence (4.8\% including both diabetes 1 and 2 in individuals aged 20-79) in 2012. This large number of diabetes in Indonesia will certainly affect the incidence of depressive symptoms. The incidence of diabetes in West Sumatera is $5.7 \%[3,4]$.

The prevalence of depressive symptoms is higher among people with diabetes compared with the general populations. These associations may be related to increased risk of depressive symptoms in an individual with diabetes. Depressive symptoms are associated with worse outcomes in the natural history of type 2 diabetes mellitus [5].

The objectives of this study are to find the percentage of depressive symptoms and the most appeared clinical manifestation in depressive symptoms, especially in Padang, West Sumatera, Indonesia. Depressive symptoms in diabetes will decrease the quality of life of diabetic patients because it may lead to poorer outcomes and increased risk of complications by lowering adherence to glucose monitoring, exercise, diet, and

How to cite this article: Decroli E, Kam A, Dillasamola D. The percentage of depressive symptoms in patients with type 2 Diabetes Mellitus in M Djamil General Hospital Padang, Indonesia. J Res Pharm. 2019; 23 (2): 292-297 
medication regimens. Depressive symptoms may also cause additive functional impairment and lead to increased costs and utilization of health care in diabetic populations.

\section{RESULTS}

\subsection{Baseline Characteristics}

A total of 2016 patient participated in this study. Female patients were $1133(56.2 \%)$ and male patients were $883(43.8 \%)$. Less than 50 years old was $582(28.9 \%)$, and more than 50 years old were $1434(71.1 \%)$. Patients having type 2 diabetes for less than 5 years were 1051 (52.1\%), more than 5 years were 965 (47.9\%), obese $457(22.7 \%)$, hypertension 1014 (50.3\%), hypertriglyceridemia 798 (39,6\%), and hypo high density lipoprotein $884(43.8 \%)$.

Based on their medication, $1027(42.3 \%)$ patients used oral antidiabetic drugs, 722 (31.7\%) used insulin, and $267(13.2 \%)$ patients used diet modification. The most common complication is neuropathy $1256(62.3 \%)$, heart disease 1021 (50.6\%), and diabetic nephropathy 958 (47.5\%). We found 235 (11.7\%) patients have depressive symptoms.

\subsection{Percentage of depressive symptoms in T2DM patients}

There are $235(11.7 \%)$ patients with depressive symptoms. Additionally, each variable showed a significant difference in this group: female vs. male (63 vs. 37\%); less than 50 years' old vs. more than 50 years' old (59.6 vs. $40.4 \%$ ); diagnosed for more than five years vs. diagnosed for less than five years (76.6 vs. $23.4 \%$ ); obese vs. non-obese ( 68.1 vs. $31.9 \%)$; hypertension vs. non-hypertension (75.7 vs. $24.3 \%)$; hypertriglyceridemia vs. non-hypertriglyceridemia (71.5 vs. $28.5 \%$ ); hypo high density lipoprotein (HDL) vs. non-hypo HDL (57.4 vs. $42.6 \%$ ); diabetic nephropathy vs. diabetic neuropathy vs. heart disease ( 52.8 vs. 27.7 vs. $19.6 \%$ ); oral antidiabetic drug therapy vs. insulin therapy vs. diet only (70.2 vs. 28.1 vs $1.7 \%)$. All of these variables were significantly different (Table 1).

Table 1. Baseline samples characteristics for the overall sample, for depressive symptoms and nondepressive symptoms.

\begin{tabular}{|c|c|c|c|c|c|}
\hline Variables & \multirow{2}{*}{$\begin{array}{l}\text { Depressive } \\
\text { Symptoms } \\
\mathrm{N}=235(\mathbf{1 1 . 7 \% )}\end{array}$} & \multirow{2}{*}{$\begin{array}{l}\text { Non-depressive } \\
\text { Symptoms } \\
\mathrm{N}=1781(88.3 \%)\end{array}$} & \multirow{2}{*}{$\begin{array}{l}\text { Total } \\
N=2016(100 \%)\end{array}$} & \multirow[t]{2}{*}{ Chi square } & \multirow[t]{2}{*}{ P-value } \\
\hline & & & & & \\
\hline \multicolumn{6}{|l|}{ 1. Gender } \\
\hline Male & $87(37.0)$ & $796(44.7)$ & $883(43.8)$ & 4.965 & $<0.05$ \\
\hline Female & $148(63.0)$ & $985(55.3)$ & $1133(56.2)$ & & \\
\hline \multicolumn{6}{|l|}{ 2. Age Group } \\
\hline$<50$ yo & $140(59.6)$ & $442(24.8)$ & $582(28.9)$ & 122.133 & $<0.05$ \\
\hline$>50$ yo & $95(40.4)$ & $1339(75.2)$ & $1434(71.1)$ & & \\
\hline \multicolumn{6}{|l|}{ 3. Duration of T2DM } \\
\hline$<5$ years & $55(23.4)$ & 996 (55.9) & $1051(52.1)$ & 87.979 & $<0.05$ \\
\hline$>5$ years & $180(76.6)$ & 785 (44.1) & $965(47.9)$ & & \\
\hline \multicolumn{6}{|l|}{ 4. Nutritional Status } \\
\hline Obese & $160(68.1)$ & $297(16.7)$ & $457(22.7)$ & 312.997 & $<0.05$ \\
\hline Non-obese & $75(31.9)$ & $1484(83.3)$ & $1559(77.3)$ & & \\
\hline \multicolumn{6}{|l|}{ 5. Hypertension Status } \\
\hline Hypertension & $178(75.7)$ & $836(46.9)$ & $1014(50.3)$ & 68.904 & $<0.05$ \\
\hline Non-Hypertension & $57(24.3)$ & $945(53.1)$ & $1002(49.7)$ & & \\
\hline \multicolumn{6}{|l|}{ 6. Triglyceridemia Profile } \\
\hline Hypertriglyceridemia & $168(71.5)$ & $630(35.4)$ & 798 (39.6) & 113.232 & $<0.05$ \\
\hline Non-Hypertriglyceridemia & $67(28.5)$ & $1151(64.6)$ & $1218(60.4)$ & & \\
\hline \multicolumn{6}{|l|}{ 7. HDL Profile } \\
\hline Hypo HDL & $135(57.4)$ & 749 (42.1) & $884(43.8)$ & 19.976 & $<0.05$ \\
\hline Non-Hipo HDL & $100(42.6)$ & $1032(57.9)$ & $1132(56.2)$ & & \\
\hline \multicolumn{6}{|l|}{ 8. Complication } \\
\hline Diabetic neuropathy & $65(27.7)$ & $1191(39.7)$ & $1256(62.3)$ & 65.543 & $<0.05$ \\
\hline Heart disease & $46(19.6)$ & $975(32.5)$ & $1021(50.6)$ & & \\
\hline Diabetic nephropathy & $124(52.8)$ & $834(27.8)$ & $958(47.5)$ & & \\
\hline \multicolumn{6}{|l|}{ 9. Medication } \\
\hline Diet only & $4(1.7)$ & $263(14.8)$ & $267(13.2)$ & 6.912 & $<0.05$ \\
\hline Oral antidiabetic drug & $165(70.2)$ & $862(48.4)$ & $1027(51.0)$ & & \\
\hline Insulin & $66(28.1)$ & $656(36.8)$ & $722(35.8)$ & & \\
\hline
\end{tabular}




\subsection{Clinical manifestation in 235 patients with depressive symptoms}

There is nine symptoms group in CESD-R that fulfilled by the patients. From 235 patients with depressive symptoms, we found the most appeared clinical manifestation are fatigue $(88.08 \%)$, loss of interest $(52.34 \%)$, sadness $(41.7 \%)$, poor concentration $(40.42 \%)$, and agitation $(23.83 \%)$ (Table 2$)$.

Table 2. Clinical manifestation in 235 patients with depressive symptoms.

\begin{tabular}{lll}
\hline Clinical Manifestation & $\mathbf{N}$ & $\mathbf{( \% )}$ \\
\hline Sadness & 98 & 41.7 \\
Loss of interest & 123 & 52.43 \\
Appetite & 13 & 5.53 \\
Sleep deprivation & 45 & 19.14 \\
Poor concentration & 95 & 40.42 \\
Guilt & 34 & 14.46 \\
Fatigue & 207 & 88.08 \\
Agitation & 56 & 23.93 \\
Suicidal ideation & 0 & 0 \\
\multicolumn{1}{c}{ Total } & & \\
\hline
\end{tabular}

\section{DISCUSSION}

The incidence of depressive symptoms in diabetes mellitus in this study was $11.7 \%$. Clinical manifestations of depressive symptoms in patients with type 2 diabetes mellitus (T2DM) in Dr. M. Djamil Hospital are the same as the general population, such as sadness, loss of interest or pleasure, feeling guilty or low self-worth, disturbed sleep or appetite, feeling of tiredness, and poor concentration. Ismail (2017) in his study stated that depressive symptoms are present in $14.1 \%$ of patients with diabetes mellitus $[5,6]$.

Prevalence of depressive symptoms in diabetic patients in several studies ranges from 15-35\%. Mezuk (2008) stated that diabetes mellitus is associated with an increased risk of depression, with a relative risk of 1.15 (95\% CI 1.02-1.30). This is confirmed in other studies that stated the risk of depression increases by two to three times in patients with diabetes mellitus [7-9].

In this study, we found depressive symptoms were more common in women. This is relevant to previous studies by Sun (2016) and Jacob (2016). Sun (2016) suggested that sex difference could be due to lifestyle factors. Most of the women in Chinese society, as well as Padang, normally spend most of their time at home, which may lead to lower physical activity and poor eating habits $[10,11]$.

Younger patients were more likely to have depressive symptoms in this study. This was a contrast from the previous study that found patients more than 65 years old had a higher risk of developing depressive symptoms. This discrepancy might be a result of patients' denial of diabetic status and diabetes complications possibility that they might have in the next years. [10,11]

In this study, longer diabetes duration was associated with higher depressive symptoms. This finding was consistent with other studies that suggested the longer diabetic duration, the higher number of diabetes complications they could have. Diabetes complications such as neuropathy, nephropathy, and heart disease may increase susceptibility to depressive symptoms. This study also found that there was an association between diabetes comorbid, like obese, hypertension, and dyslipidemia with more depressive symptoms in diabetic patients. Katon (2008) found that patient with comorbidity are 3 times to be nonadherent to treatment recommendation and lack of self-care. Self-care in diabetes includes adherence to dietary restrictions, adequate physical activity, taking medication as prescribed, and blood glucose monitoring [12].

The most appeared clinical manifestation in a depressive symptoms group is fatigue $(88.08 \%)$, loss of interest $(52.34 \%)$, sadness (41.7\%), poor concentration (40.42\%), and agitation (23.83\%). Kalra (2018) suggested that prominent symptoms of fatigue in the majority of patients with depression. Fatigue is often associated with impaired concentration, irritability, and reduced productivity [13].

In this study, we found that oral antidiabetic group is more than insulin and diet the only group. Previous studies stated that depressive symptoms are found more in people with diabetes who only use an oral antidiabetic drug. The increased amount of antidiabetic drug consumption could have stressed and 
burdened patient's feelings that causing depressive symptoms. But, we didn't find which oral antidiabetic drug causes more depressive symptoms [14].

Increased of depressive symptoms in patients using an oral antidiabetic drug also found by Berge (2015). The possible explanation is that treatment with the oral antidiabetic drug can cause depressive symptoms, but we didn't find any support for this finding. Berge (2015) assume that those with oral antidiabetic drug have a disease that is more difficult to treat. The more oral antidiabetic drug is consumed by patients, the more difficult to control diabetes that they suffered. We assumed that patients consuming oral antidiabetic drug were afraid of negative effect in long-term drug use [15].

However, Noh (2005) stated that insulin therapy in diabetic patients causes more depressive symptoms than patients who take oral antidiabetic drugs. Meanwhile, Berge (2012) stated that depressive symptoms are more prevalent in a group of patients using a combination of oral antidiabetic drug and insulin [16-18].

In this study, we found that patients with diabetic nephropathy are more than diabetic neuropathy and heart disease. The dialysis process and the feelings that this is the end of the disease could increase depressive symptoms. Previous meta-analysis study stated that there is a relationship between depressive symptoms with macrovascular and microvascular complications. Nouwen (2015) stated that depression in diabetes will increase the risk of macrovascular and microvascular complications. Previous studies also stated that there is a link between depressive symptoms and macrovascular complications, which was a myocardial infarction $[5,19,20]$.

$\mathrm{Yu}$ (2013) found an association between depression with diabetes and chronic kidney disease. Yu suggested that depression is associated with proinflammatory cytokines and this proinflammatory state has been linked with an increased risk of diabetic nephropathy. Takasaki (2016) also found that the progression of diabetic nephropathy is likely to be associated with increased risk and severity of depression [21,22].

\section{CONCLUSION}

The percentage of depressive symptoms in a patient with type 2 diabetes mellitus is $11.7 \%$. The most appeared clinical manifestation in 235 patients with depressive symptoms is fatigue, loss of interest, sadness, poor concentration, and agitation. There are more depressive symptoms in patients consuming oral antidiabetic drug than patients using insulin and diet only. More depressive symptoms are also found in patients with diabetic nephropathy than patients with diabetic neuropathy and heart disease. These findings showed that there are many depressive symptoms in patients with T2DM, and some of most appeared clinical manifestation in depressive symptoms should be considered.

\section{MATERIALS AND METHODS}

We conducted a secondary analysis of data obtained in M Djamil General Hospital Padang, West Sumatera, Indonesia from January 2017 until December 2017. Dr. M. Djamil General Hospital is a type A, national referred hospital for West Sumatera region and an educational hospital. Diabetic patients' referral visit to a diabetic clinic reaches approximately $100-200$ patients per day.

All T2DM outpatients in this hospital were eligible to participate in the study. T2DM was confirmed by fasting blood glucose levels and HbA1c. They have agreed to participate and signed the informed consent form. There are no patients with prediabetic included in this study. Patients with depression history and consuming any antidepressant were excluded. Patients with Severe Cognitive or Language Deficits were excluded. Demographic and clinical data, such as gender, age, duration of diabetes, nutritional status, hypertension status, triglyceridemia profile, high-density lipoprotein profile, type of complications, type of diabetes medications was determined from patient's medical records. We defined nutritional status by calculating body mass index (BMI). BMI more than $25 \mathrm{~kg} / \mathrm{m}^{2}$ defined as obese. Age group divided by 50 years old according to Charlson Comorbidity Index. Triglyceridemia profile and high-density lipoprotein profile are part of dyslipidemia. Ethical approval was granted by the Medical Faculty University of Andalas Research Ethics Committee.

Depressive symptoms were assessed at visit using The Center for Epidemiologic Studies Depression Scale-Revised (CESD-R), a 20-item questionnaire in nine clinical manifestation group developed to assess depressive symptoms in a community population. Van Dam (2011) suggested the CESD-R is an accurate and valid measure of depressive symptoms in the general population [23]. The CESD-R items represent the major components of depression and include depressed mood, feelings of worthlessness, feelings of hopelessness, loss of appetite, poor concentration, and sleep disturbance. Participants were interviewed by internist in the diabetic clinic to rate each item on a scale from 0 to 3 based on "how often you felt this way during the past 
week." The interview was carried out about 30 minutes. Scores range from 0 to 60 , with higher scores indicating more severe depressive symptoms. For the purpose of our analyses, depressive symptoms were defined by a CESD-R score of 16 or higher.

We compared a number of occurrence in patients with depressive symptoms based on demographics, clinical data, type of diabetic medication they consumed (diet only, oral antidiabetic, and insulin) and diabetic complication. We used chi-square analysis to compared variables in this study. The level of statistical significance was $5 \%$. This data analyzed by SPSS 22.0 .

Acknowledgement: This research was supported by M Djamil General Hospital Padang, Indonesia.

Author contributions: Concept - E.D.; Design - E.D., A.K., D.D.; Supervision - E.D.; Materials - E.D., A.K., D.D.; Data Collection and/or Processing - E.D., A.K.; Analysis and/or Interpretation - E.D., A.K., D.D.; Literature Search - E.D., A.K., D.D.; Writing - E.D.; Critical Reviews - E.D., A.K., D.D.

Conflict of interest statement: There is no conflict of interest in this study and publication.

\section{REFERENCES}

[1] Eker S. Prevalence of depression symptoms in Diabetes Mellitus. Open Access Maced J Med Sci. 2018; 6(2): 340-343. [CrossRef]

[2] Joseph JJ, Golden SH. Cortisol dysregulation: The bidirectional link between stress, depression, and type 2 diabetes mellitus. Ann N Y Acad Sci. 2017; 1391(1): 20-34. [CrossRef]

[3] Soewondo P, Ferrario A, Tahapary DL. Challenges in diabetes management in Indonesia: A literature review. Global Health. 2013; 9: 63. [CrossRef]

[4] Syafrita Y, Amir D, Decroli E. The associations of plasma levels of beta amyloid, insulin, insulin-degrading enzyme and receptor of advanced glycosylation end product with cognitive impairment in type 2 diabetes mellitus patients. Turk J Immunol. 2017; 5(2): 31-35. [CrossRef]

[5] Ismail K, Moulton CD, Winkley K, Pickup JC, Thomas SM, Sherwood RA, Stahl D, Amiel SA. The association of depressive symptoms and diabetes distress with glycaemic control and diabetes complications over 2 years in newly diagnosed type 2 diabetes: A prospective cohort study. Diabetologia. 2017; 60(10): 2092-2102. [CrossRef]

[6] Wang L, Song R, Chen Z, Wang J, Ling F. Prevalence of depressive symptoms and factors associated with it in type 2 diabetes patients: a cross-sectional study in China. BMC Public Health. 2015; 15: 188-192. [CrossRef]

[7] Wang J, Wu X, Lai W, Long E, Zhang X, Li W, Zhu Y, Chen C, Zhoung X, Liu Z, Wang D, Lin H. Prevalence of depression and depressive symptoms among outpatients: a systematic review and meta-analysis. BMJ Open. 2017; 7: e017173. [CrossRef]

[8] Mezuk B, Eaton WW, Albrecht S, Golden SH. Depression and type 2 diabetes over the lifespan: a meta-analysis. Diabetes Care. 2008; 31(12): 2383-2390. [CrossRef]

[9] Demakakos P, Pierce MB, Hardy R. Depressive symptoms and risk of type 2 diabetes in a national sample of middleaged and older adults. Diabetes Care. 2010; 33(4): 792-797. [CrossRef]

[10] Sun N, Lou P, Shang Y, Zhang P, Wang J, Chang G, Shi C. Prevalence and determinant of depressive and anxiety symptoms in adults with type 2 diabetes in China: A cross-sectional study. BMJ Open. 2016; 6: e012540. [CrossRef]

[11] Jacob L, Kostev K. Prevalence of depression of type 2 diabetes patients in German primary care practices. J Diabetes Complications. 2016; 30(3): 432-437. [CrossRef]

[12] Katon WJ. The comorbidity of diabetes mellitus and depression. Am J Med. 2008; 121(11 Suppl 2): S8-15. [CrossRef]

[13] Kalra S, Sahay R. Diabetes fatigue syndrome. Diabetes Ther. 2018; 9(4): 1421-1429. [CrossRef]

[14] Ciechanowski PS, Katon WJ, Russo JE. Depression and diabetes: Impact of depressive symptoms on adherence, function, and costs. Arch Intern Med. 2000; 160(21): 3278-3285. [CrossRef]

[15] Berge LI, Riise T, Tell GS, Iversen MM, Ostbye T, Lund A, Knudsen AK. Depression in persons with diabetes by age and antidiabetic treatment: A cross-sectional analysis with data from the Hordaland Health Study. Plos One. 2015; 10(5): e0127161. [CrossRef]

[16] Noh JH, Park JK, Lee HJ, Kwon SK, Lee SH, Park JH, Ko KS, Rhee BD, Lim KH, Kim DJ. Depressive symptoms of type 2 diabetics treated with insulin compared to diabetics taking oral anti-diabetic drugs: Korean study. Diabetes Res Clin Pract. 2005; 69(3): 243-248. [CrossRef] 
[17] Berge LI, Riise T, Fasmer OB, Lund A, Oedegaard KJ, Hundal O. Risk of depression in diabetes is highest for young persons using oral anti-diabetic agents. Diabet Med. 2012; 29: 509-514. [CrossRef]

[18] Masrul, Decroli E, Purnakarya I, Lipoeto NI. Effect of modified diet and exercise on insulin level in diabetes mellitus type-2 patients. Pak J Nutr. 2016; 15: 370-373. [CrossRef]

[19] de Groot M, Anderson R, Freedland KE, Clouse RE, Lustman PJ. Association of depression and diabetes complications: A meta-analysis. Psychosom Med. 2001 Jul-Aug; 63(4): 619-630. [CrossRef]

[20] Nouwen A. Depression and diabetes distress. Diabet Med. 2015; 32: 1261-1263. [CrossRef]

[21] Yu MK, Katon W, Young BA. Diabetes self-care, major depression, and chronic kidney disease in an outpatient diabetic population. Nephron Clin Pract. 2013; 124: 106-112. [CrossRef]

[22] Takasaki K, Babazono T, Ishizawa K, Miura J, Uchigata Y. Relationship between diabetic nephropathy and depression: A cross-sectional analysis using the diabetes study from the Center of Tokyo Women's Medical University (DIACET). BMJ Open Diabetes Res Care. 2016; 4: e000310. [CrossRef]

[23] Van Dam NT, Earleywine M. Validation of the Center for Epidemiologic Studies Depression Scale - Revised (CESDR): Pragmatic depression assessment in the general population. Psychiatry Res. 2011; 186(1): 128-132. [CrossRef] 